\title{
Theoretically proposed optimal frequency for ultrasound induced cartilage restoration
}

\author{
April D. Miller ${ }^{1,2^{*}} \mathbb{D}$, Anuradha Subramanian ${ }^{1}$ and Hendrik J. Viljoen ${ }^{1}$
}

\author{
* Correspondence: \\ april.miller17@huskers.unl.edu \\ ${ }^{1}$ Department of Chemical and \\ Biomolecular Engineering, \\ University of Nebraska-Lincoln, 207 \\ Othmer Hall, Lincoln, NE 68588, USA \\ ${ }^{2}$ Department of Chemistry and Life \\ Science, United States Military \\ Academy, West Point, NY 10996, \\ USA
}

\begin{abstract}
Background: Matching the frequency of the driving force to that of the system's natural frequency of vibration results in greater amplitude response. Thus we hypothesize that applying ultrasound at the chondrocyte's resonant frequency will result in greater deformation than applying similar ultrasound power at a frequency outside of the resonant bandwidth. Based on this resonant hypothesis, our group previously confirmed theoretically and experimentally that ultrasound stimulation of suspended chondrocytes at resonance $(5 \mathrm{MHz})$ maximized gene expression of load inducible genes. However, this study was based on suspended chondrocytes. The resonant frequency of a chondrocyte does not only depend on the cell mass and intracellular stiffness, but also on the mechanical properties of the surrounding medium. An in vivo chondrocyte's environment differs whether it be a blood clot (following microfracture), a hydrogel or the pericellular and extracellular matrices of the natural cartilage. All have distinct structures and compositions leading to different resonant frequencies. In this study, we present two theoretical models, the first model to understand the effects of the resonant frequency on the cellular deformation and the second to identify the optimal frequency range for clinical applications of ultrasound to enhance cartilage restoration.
\end{abstract}

Results: We showed that applying low-intensity ultrasound at the resonant frequency induced deformation equivalent to that experimentally calculated in previous studies at higher intensities and a $1 \mathrm{MHz}$ frequency. Additionally, the resonant frequency of an in vivo chondrocyte in healthy conditions, osteoarthritic conditions, embedded in a blood clot and embedded in fibrin ranges from $3.5-4.8 \mathrm{MHz}$.

Conclusion: The main finding of this study is the theoretically proposed optimal frequency for clinical applications of therapeutic ultrasound induced cartilage restoration is $3.5-4.8 \mathrm{MHz}$ (the resonant frequencies of in vivo chondrocytes). Application of ultrasound in this frequency range will maximize desired bioeffects.

Keywords: Resonant frequency, Mechanical energy density, Cellular deformation

\section{Background}

Osteoarthritis and cartilage injuries are major biomedical burdens in the United States that affect millions of Americans as cartilage is an avascular, aneural tissue with limited capacity of self-repair. Currently, there are a variety of surgical procedures available to treat articular cartilage, two common methods are microfracture and autologous chondrocyte transplantation (ACI). Microfracture is the first-line treatment for smaller cartilage lesions and involves perforating the subchondral plate to recruit mesenchymal

(c) The Author(s). 2017 Open Access This article is distributed under the terms of the Creative Commons Attribution 4.0 International License (http://creativecommons.org/licenses/by/4.0/), which permits unrestricted use, distribution, and reproduction in any medium, provided you give appropriate credit to the original author(s) and the source, provide a link to the Creative Commons license, and indicate if changes were made. The Creative Commons Public Domain Dedication waiver (http://creativecommons.org/ publicdomain/zero/1.0/) applies to the data made available in this article, unless otherwise stated. 
cells (MSC) from the bone marrow [1, 2]. Although the procedure has demonstrated excellent short-term clinical outcomes, the long-term durability of the tissue has shown functional decline as a result of inefficient chondrogenesis of egressed MSCs [3]. ACI and newer cell-based techniques (which include the use of MSCs) are preferred for larger lesions and involves extracting cartilage/cells from the patient followed by reimplantation [2-4]. However, the high cost of the procedure makes it less appealing.

Mechanical and structural cues delivered to the chondrocyte play a central role in the tissue physiology [5]. Thus there is considerable research in techniques to affect the functional adaptation of cartilage [6]. One method known to modulate chondrocytes' metabolic activity is mechanical stimulus although the mechanisms are only partly understood. The mechanical signals transmitted to the chondrocyte induce extracellular matrix synthesis and maintenance which alters the cartilage structure and composition [7]. A mechanical stimulus believed to trigger signal transduction and induce bioeffects is cellular deformation [8]. Two techniques that have been shown to induce cellular deformation are dynamic compression and ultrasound and both have also been shown to stimulate proteoglycan and collagen II [9-14]. Thus, a beneficial sequential step in all cartilage restoration techniques should involve method(s) to stimulate the chondrocyte to increase the physical function of the restored tissue such as ultrasound.

Low-intensity ultrasound (LIUS) can be delivered using a handheld portable system that can be easily applied in the comfort of patients' homes. Ultrasound transmits mechanical energy by perturbing cells around their equilibrium position [15] and has been shown to induce cellular deformation in red blood cells, macrophages, MC3T3E1 and Human Airway Smooth Muscle cells at various frequencies with pressure amplitudes ranging from $12 \mathrm{kPa}$ to $1000 \mathrm{kPa}$ [14, 16-19]. During controlled compression studies, [8] showed that cellular deformation is transmitted to the nucleus through the cytoskeleton, specifically, actin microfilaments. While, [20] confirmed that ultrasound was transmitted to the nucleus by studying the effects of ultrasound on chromatin remodeling. They showed that ultrasound induces chromatin remodeling in chondrocytes and fibroblasts.

Most published in vivo and in vitro cartilage restoration applications use the empirically derived low-intensity pulsed ultrasound (LIPUS) regimens for bone, $1.0-1.5 \mathrm{MHz}$, and thus leads to variable results [21-25]. To optimize the regime for cartilage repair [26] theoretically determined that suspended chondrocytes have a primary resonance of $5.2 \pm 0.8 \mathrm{MHz}$. Resonance occurs when there is a match between the ultrasound frequency and the elastic properties of the material which generates an increase in the amplitude of displacement [27]. Therefore at this frequency ultrasound will increase the oscillating displacement amplitude in the cell and maximize the mechanical energy coupled to the cell [26]. These findings were further extended to experimental validation using a monolayer of cells and measuring load-inducible gene expression (c-fos, c-jun and c-myc) which showed that ultrasound applied at the resonant frequency of $5 \mathrm{MHz}$, compared to 2 and $8 \mathrm{MHz}$, resulted in increased gene expression [26]. Additional experiments, also using a monolayer of cells, confirmed these findings and showed enhanced cellularity and increased matrix and protein synthesis at this resonant frequency $[28,29]$. Thus ultrasound maximizes bioeffects when applied at resonance. However, the theoretical model developed to calculate this resonant frequency lacks the biomechanical environment of the in vivo chondrocyte. 
The mechanical environment of the chondrocyte plays an important role in cartilage homeostasis. An in vivo chondrocyte following a microfracture procedure is embedded in a blood clot while that following an ACI procedure could be embedded in a hydrogel [30] or native cartilage. An in vivo chondrocyte in native cartilage is embedded in the extracellular matrix (ECM) and surrounded by a narrow region termed the pericellular matrix (PCM) that has a distinct structure and composition that differs from the chondrocyte and ECM [31]. Although the role of the PCM is not fully understood, theoretical models have shown that it plays a major biomechanical role in cell-matrix interactions and serves as a mechanical transducer [32-35]. The contribution of a blood clot, hydrogel or the ECM and PCM may cause a shift in the resonant frequency of an in vivo chondrocyte from that of a suspended chondrocyte. Additionally, osteoarthritis results in degeneration of cartilage and alters the internal structure and material properties [36]. As the resonant frequency is highly dependent on the mass and stiffness, osteoarthritis can also cause a shift in the optimal frequency.

In this study we first present a theoretical model of a suspended chondrocyte to show the effects of continuous ultrasound applied at resonance on cellular deformation. Second, theoretical models of a chondrocyte embedded in a blood clot, embedded in a fibrin hydrogel and surrounded by the PCM and embedded in the ECM are presented to calculate the resonant frequencies of in vivo chondrocytes in different mechanical environments. A range of parameters for the PCM and ECM are reported throughout literature, thus we identify the resonant frequency over a range of mechanical properties and for those properties identified in an osteoarthritis environment.

\section{Methods: Mathematical modeling}

Ultrasound induced cellular deformation

To theoretically study the effects of frequency on ultrasound induced deformation, the response of a suspended chondrocyte was modeled using the finite element method and facilitated by COMSOL Multiphysics' built-in Acoustics-Poroelastic Waves Interface (COMSOL Inc., Burlington, MA, USA). Biot's theory is used to model the cytoplasm and nucleus which is the basis of the governing equations in the Poroelastic Waves Module [37, 38]. Time-harmonic dependence, $p(x, t)=p(x) e^{i \omega t}$ is assumed which is the case for the application of continuous ultrasound stimulation. The governing equations are given by eqns. $1-2$.

$$
\begin{aligned}
& -\left(\rho_{a v}-\frac{\rho_{f}^{2}}{\rho_{c}(\omega)} \mathbf{u}\right) \omega^{2} \mathbf{u}-\nabla \cdot\left(\boldsymbol{c}: \boldsymbol{\varepsilon}-\alpha_{B} p_{f} \boldsymbol{I}\right)=\frac{\rho_{f}}{\rho_{c}(\omega)} \nabla p_{f} \\
& \nabla \cdot\left(-\frac{1}{\rho_{c}}\left(\nabla \boldsymbol{p}-\boldsymbol{\omega}^{2} \boldsymbol{\rho}_{\boldsymbol{f}} \boldsymbol{u}\right)\right)-\frac{k_{e q}^{2} p}{\rho_{c}}=\omega^{2} \alpha_{B} \nabla \cdot \mathbf{u}
\end{aligned}
$$

Eqns. 3-5 define $\rho_{a v}$, the average density, $\rho_{c}$, the complex density and $k_{e q}$, the wavenumber. $\mathbf{u}$ is the displacement vector, $\omega$ is angular frequency, $c$ is the elasticity tensor, $\varepsilon$ is the strain tensor and $p$ is pressure.

$$
\begin{aligned}
& \rho_{a v}=\rho_{d}+\epsilon_{P} \rho_{f} \\
& \rho_{c}=\frac{\tau_{\infty} \rho_{f}}{\epsilon_{P}}+\frac{\mu_{f}}{i \omega k_{P}}
\end{aligned}
$$




$$
k_{e q}^{2}=\left(\epsilon_{P} X_{f}+\frac{\alpha_{B}-\epsilon_{P}}{K_{d}}\left(1-\alpha_{B}\right)\right) \omega^{2} \rho_{c}
$$

Louw [26] calculated the resonant frequency of suspended chondrocytes, thus the variables and values used in [26] and defined in Table 1 are used for this study.

Following [26] the cell was modeled as four concentric spheres; the nucleus, cytoplasm, nuclear envelope and cellular membrane. The cell and nuclear radii were 6.5 and $3.5 \mu \mathrm{m}$, respectively [39, 40], and thicknesses of the plasma membrane and nuclear envelope were 15 and $40 \mathrm{~nm}$, respectively [41]. Each domain was modeled as a biphasic medium [39, 42-46]. The geometry consists of a suspended cell in a cylinder (well of a culture plate) filled with growth media. The ultrasound source was positioned below the cell, as shown in Fig. 1a, and the cell's position is dependent on frequency to ensure the location of the cell was at an antinode. This forces the pressure amplitude at the chondrocyte's position to remain constant between frequencies to allow for direct comparison. Water properties are used for the growth media and two pressure amplitudes were studied, the amplitude used in [26], $14 \mathrm{kPa}$, and the amplitude used in [14], $170 \mathrm{kPa}$. Two boundary conditions were used in this study, a sound hard boundary layer which assumes zero for the normal component of acceleration and cylindrical wave radiation where the outgoing wave leaves with minimal reflection [38].

Table 1 Material properties used in the Biot theory

\begin{tabular}{|c|c|c|c|}
\hline \multicolumn{4}{|l|}{ Cytoplasm } \\
\hline \multicolumn{4}{|l|}{ Bulk Medium } \\
\hline Bulk Modulus (Pa) & $K_{d}$ & 500 & {$[26]$} \\
\hline Poisson's Ratio & $v$ & 0.38 & {$[42]$} \\
\hline Bulk Density $\left(\mathrm{kg} / \mathrm{m}^{3}\right)$ & $\rho_{d}$ & 300 & {$[57]$} \\
\hline Permeability $\left(\mathrm{m}^{2}\right)$ & $k_{p}$ & $7 \times 10^{-19}$ & $\mu_{f} / \bar{\omega}$ \\
\hline Porosity & $\epsilon_{p}$ & 0.75 & {$[57]$} \\
\hline Biot-Willis Coefficient & $a_{B}$ & 0.9999 & $1-K / K_{s}$ \\
\hline Tortuosity Factor & $\tau_{\infty}$ & 1.2 & {$[58]$} \\
\hline \multicolumn{4}{|l|}{ Fluid Phase } \\
\hline Density $\left(\mathrm{kg} / \mathrm{m}^{3}\right)$ & $\rho_{f}$ & 992.52 & {$[59]$} \\
\hline Vicosity (Pa·s) & $\mu_{f}$ & $0.7 \times 10^{-3}$ & [60] \\
\hline Compressibility $(1 / \mathrm{Pa})$ & $X_{f}$ & $4.35 \times 10^{-10}$ & $1 / K_{f}$ \\
\hline \multicolumn{4}{|l|}{ Nucleus } \\
\hline \multicolumn{4}{|l|}{ Bulk Medium } \\
\hline Bulk Modulus (Pa) & $K_{d}$ & $2 \times 10^{3}$ & [39] \\
\hline Poisson's Ratio & $v$ & 0.38 & {$[26]$} \\
\hline Bulk Density $\left(\mathrm{kg} / \mathrm{m}^{3}\right)$ & $\rho_{d}$ & 400 & {$[26]$} \\
\hline Permeability $\left(\mathrm{m}^{2}\right)$ & $k_{p}$ & $7 \times 10^{-19}$ & $\mu_{f} / \bar{\omega}$ \\
\hline Porosity & $\epsilon_{p}$ & 0.65 & {$[61]$} \\
\hline Biot-Willis Coefficient & $a_{B}$ & 0.9996 & $1-K_{d} / K_{s}$ \\
\hline Tortuosity Factor & $\tau_{\infty}$ & 2 & {$[58]$} \\
\hline \multicolumn{4}{|l|}{ Fluid Phase } \\
\hline See cytoplasm fluid phase & & & \\
\hline
\end{tabular}



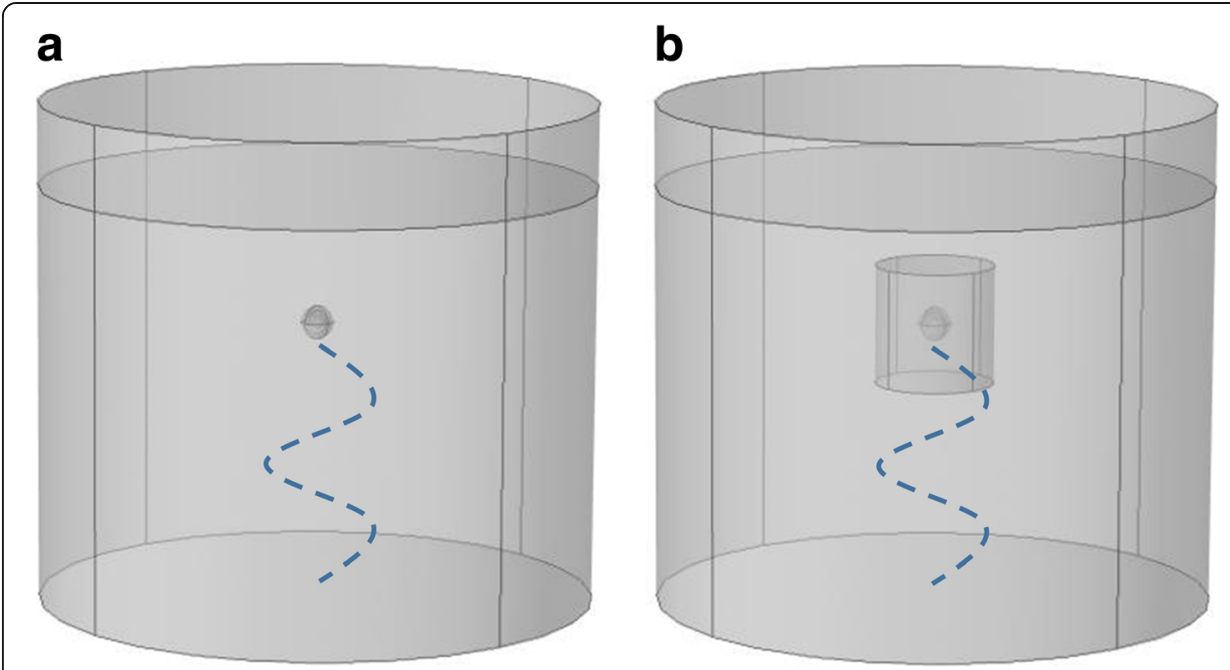

Fig. 1 Model Geometry: a) A suspended cell (indicated by the small sphere) immersed in growth media. The ultrasound source ( $14 \mathrm{kPa}$ ) is positioned at the bottom and is indicated by the blue dotted line. The cell position is frequency dependent to ensure the position remains at an antinode. $\mathbf{b}$ A chondron (indicated by the sphere) embedded in the extracellular matrix (indicated by the cylinder) and immersed in growth media. The ultrasound source is positioned at the bottom (blue dotted line). The cell position is frequency dependent

To minimize the degrees of freedom and computational cost, the geometry was reduced to a height of $3 \lambda / 4$ and a width of $\lambda / 2$, where $\lambda$ is the wavelength. (At $5 \mathrm{MHz}$ in water $\lambda=300 \mu \mathrm{m}$ which is approximately 30 cell diameters.) The geometry was meshed using a tetrahedral element which resulted in 40,000-50,000 elements (varies per frequency) and solved on an Intel Core i5 desktop computer with 16 GB RAM. A formation of a standing wave occurred as a result of the geometry dimensions and the water/ air interface which is also seen in in vitro experimental setups as a result of the air/ polystyrene interface when sonicated from above the cell and the water/air interface when sonicated from below the cell.

\section{Modeling resonant frequency}

The deformation induced by the ultrasound results in the transmission of elastic energy (stored mechanical energy) into the cell. [26] showed that an increase in this stored energy resulted in an increase in load inducible gene expression. Therefore the goal should be to maximize the energy coupled to the cell which occurs if the ultrasound is applied at the chondrocyte's resonant frequency. The final aim of the study was to calculate the resonant frequency of an in vivo chondrocyte in a blood clot, fibrin hydrogel and under a range of properties for the PCM and ECM. The frequency at which the stored mechanical energy is maximized is the resonant frequency. The stored mechanical energy, $U$, of a cell in an ultrasound field is defined by eq. 6 and has been calculated for both the nucleus and cytoplasm over a range of frequencies $(1 \mathrm{MHz}-8 \mathrm{MHz})$.

$$
U=\frac{1}{T} \int_{0}^{T} \frac{1}{2} \boldsymbol{\sigma}(\boldsymbol{t}): \boldsymbol{\varepsilon}(\boldsymbol{t}) d t
$$

$T$ is the period and $\boldsymbol{\sigma}(\boldsymbol{t})$ the stress tensor. To further reduce the degrees of freedom and computational cost to conduct the parametric sweep over the range of 
frequencies the cell was represented as two concentric spheres representing the nucleus and cytoplasm as opposed to four concentric spheres used in the deformation study. Four concentric spheres were used in the deformation study to show the effects of the contribution of the membranes. In the resonance study the aim is to identify the frequency at which the stored mechanical energy is maximized which requires the calculation over a range frequencies and has a higher computational cost. Trials were conducted using four concentric spheres to confirm the resonant frequency did not change. Additionally, an optimization study was conducted to verify the mesh was appropriate and that the resonant frequency did not shift. The mathematical formation for both was the same as that described for the deformation study, detailed above with a pressure amplitude of $14 \mathrm{kPa}$. The blood clot, fibrin hydrogel, PCM and ECM were assumed to be isotropic biphasic medium. The acoustic properties of blood clots and fibrin are obtained from [47] and shown in Table 2. The mechanical properties of the ECM is known to be depth dependent and the Young's modulus has been reported to range from approximately $100 \mathrm{kPa}$ to $2 \mathrm{MPa}$ where the middle zone is approximately $500 \mathrm{kPa}$ and deep zone $2 \mathrm{MPa}$ $[35,48,49]$. The material properties of the PCM have been experimentally shown to be approximately constant throughout the tissue depth, however a range of values from 20 to $265 \mathrm{kPa}$ for PCM's Young's modulus has been reported [33, 35, 50-52]. The range could be a result of the species, type of sample used, age or measuring technique [31]. Thus this study includes a range of parameters for both the PCM and ECM, listed in Table 2, to study the effects of the mechanical properties on the resonant frequency. The osteoarthritic Young's modulus was 60\% of the normal conditions and the hydraulic permeability is assumed to be homogeneous and isotropic [35].

The geometry as shown in Fig. 1b, mimics an explant in the well of a culture plate. The ultrasound source was positioned below the tissue and the cell's position is frequency dependent to allow a direct comparison between frequencies. The ECM was modeled as a cylinder plug with a height of $65 \mu \mathrm{m}$ and a radius of $32.5 \mu \mathrm{m}$ which is in agreement with the microscale biphasic model developed by [53] to analyze cell-matrix interactions. Larger heights and widths were also examined to verify the resonant frequency remained the same. Based on [13] measured chondron cross-sectional areas, [25] calculated the typical PCM thickness values to range from 2 to $6 \mu \mathrm{m}$, thus the resonant frequency was calculated using the properties listed in Table 2 at 2.5, $6 \mu \mathrm{m}$ and a 50\% increase in thickness for the osteoarthritic conditions [51].

Table 2 Mechanical Properties

\begin{tabular}{|c|c|c|c|c|c|c|}
\hline \multirow[t]{2}{*}{ Mechanical Properties } & \multirow[t]{2}{*}{ Blood Clot } & \multirow[t]{2}{*}{ Fibrin } & \multicolumn{2}{|l|}{ ECM } & \multicolumn{2}{|l|}{ PCM } \\
\hline & & & Normal & Osteoarthritis & Normal & Osteoarthritis \\
\hline Young's Modulus (kPa) & & & $500-2000$ & $200-600$ & $1-500$ & 25 \\
\hline Bulk Modulus (Pa) & 350.8 & 475.4 & & & & \\
\hline Shear Modulus (Pa) & 228.6 & 312.5 & & & & \\
\hline Permeability (mNs) & $1 \times 10^{-12}$ & $6 \times 10^{-15}$ & $1 \times 10^{-15}$ & $2 \times 10^{-15}$ & $4 \times 10^{-17}$ & $13 \times 10^{-17}$ \\
\hline Poisson's Ratio & & & 0.04 & 0.04 & 0.04 & 0.04 \\
\hline
\end{tabular}




\section{Results}

\section{Cellular deformation}

Ultrasound induced cellular deformation is displayed in Fig. 2. Figure 2a-c are the results of ultrasound application with an initial pressure amplitude of $14 \mathrm{kPa}$. Figure $2 \mathrm{~d}-\mathrm{f}$ are the results of ultrasound induced cellular deformation with an initial pressure amplitude of $170 \mathrm{kPa}$.

\section{In vivo resonant frequency}

The resonant frequency of a chondrocyte does not only depend on the cell mass and intracellular stiffness, but also on the mechanical properties of the surrounding medium. An in vivo chondrocyte's environment differs whether it be a blood clot (following microfracture), a hydrogel or the pericellular and extracellular matrices of the natural cartilage. All have distinct structures and compositions leading to different resonant frequencies. The resonant frequencies of a chondrocyte embedded in a blood clot, which would be the case following microfracture procedures, is shown in Fig. 3a. The effects of the presence of the PCM, with varying properties, surrounded by a blood clot is also shown in Fig. 3a. The resonant frequencies of a chondrocyte embedded in a fibrin hydrogel, which is a type of hydrogel used in ACI procedures [54, 55], is shown in Fig. 3b. The effects of the presence of the PCM, with varying properties, surrounded by a fibrin hydrogel is also shown in Fig. 3b. The effects of the PCM's mechanical properties for suspended healthy and osteoarthritic chondrons are shown in Fig. 4.

The mechanical properties of the ECM is known to be depth dependent and the Young's modulus has been reported to range from approximately $100 \mathrm{kPa}$ to $2 \mathrm{MPa}$ where the middle zone is approximately $500 \mathrm{kPa}$ and deep zone $2 \mathrm{MPa}[35,48,49]$. Thus the effects of the ECM's mechanical properties on chondrocytes' resonant frequencies are shown in Figs. 5 and 6.

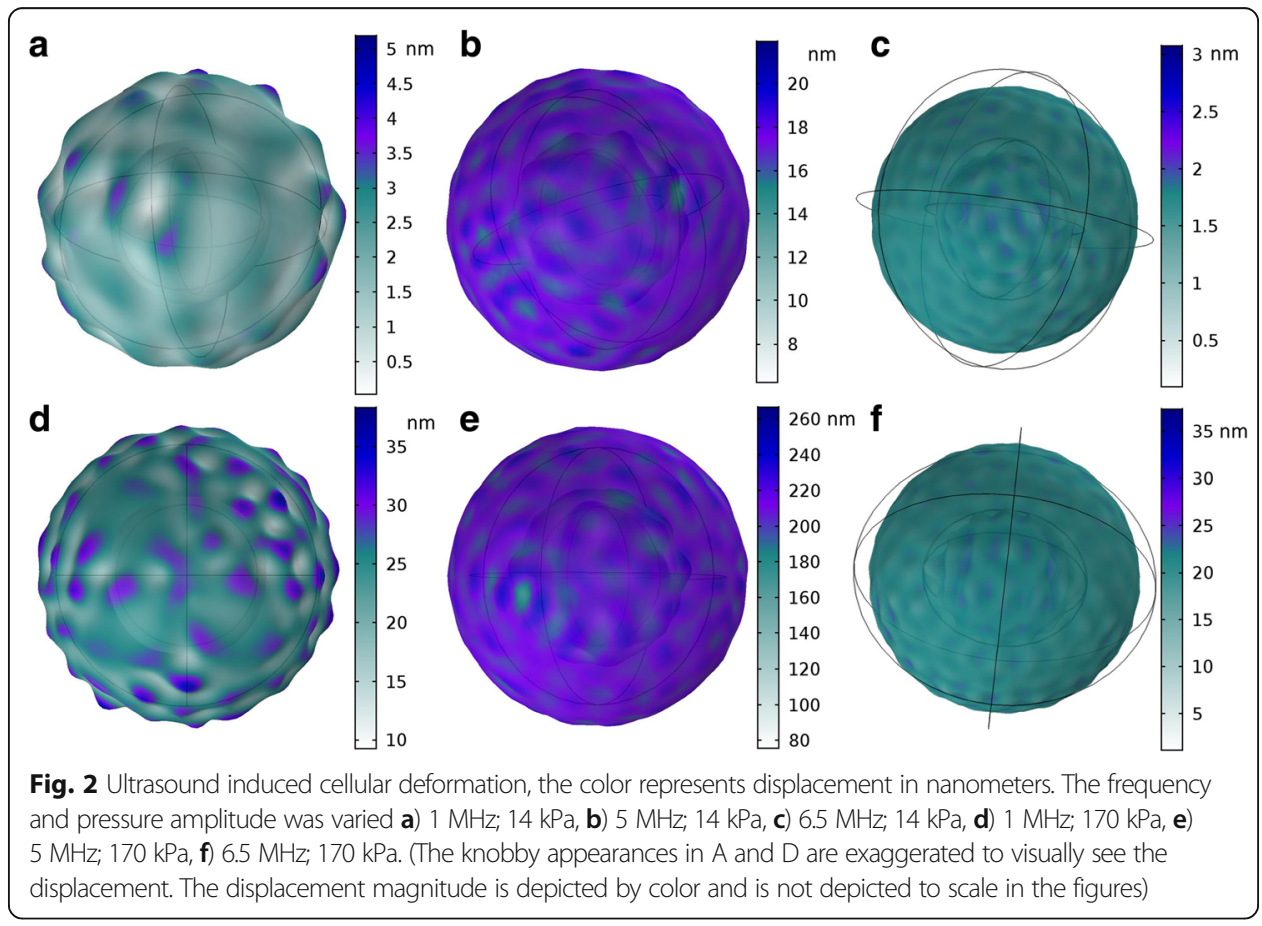



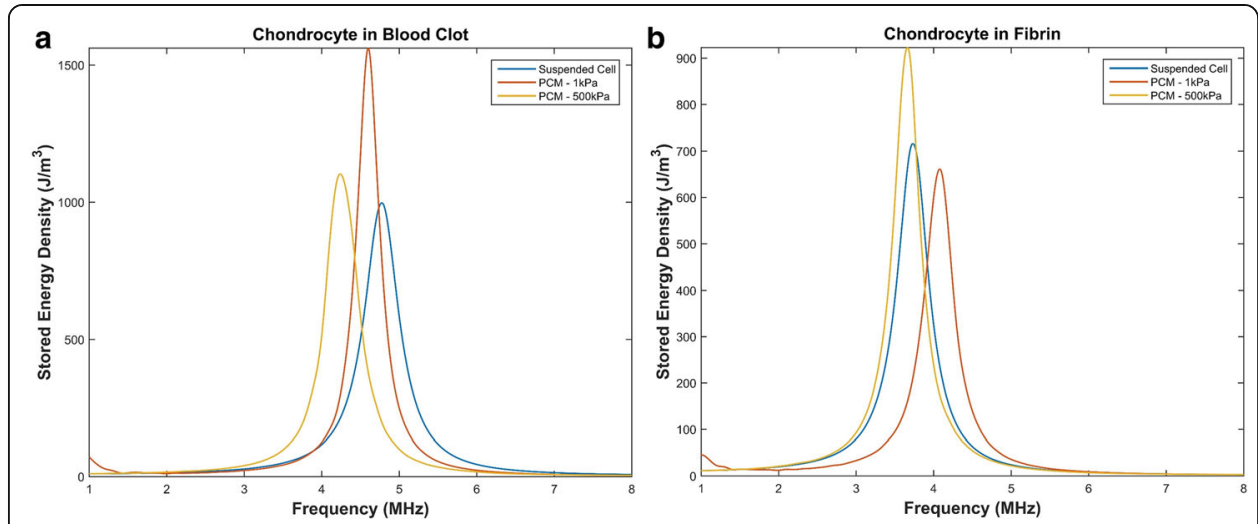

Fig. 3 Resonant frequency of a chondrocytes in a blood clot and fibrin. a A suspended cell, a chondrocyte surrounded by a PCM with a thickness of $2.5 \mu \mathrm{m}$ and a Young's modulus of $1 \mathrm{kPa}$ and a chondrocyte surrounded by a PCM with a thickness of $2.5 \mu \mathrm{m}$ and a Young's modulus of $500 \mathrm{kPa}$ embedded in a blood clot. b A suspended cell, a chondrocyte surrounded by a PCM with a thickness of $2.5 \mu \mathrm{m}$ and a Young's modulus of $1 \mathrm{kPa}$ and a chondrocyte surrounded by a PCM with a thickness of $2.5 \mu \mathrm{m}$ and a Young's modulus of $500 \mathrm{kPa}$ embedded in fibrin

\section{Discussion}

\section{Cellular deformation}

Mizrahi et al. [14] showed that ultrasound applied at $1 \mathrm{MHz}$ with an intensity amplitude of $170 \mathrm{kPa}$ induced an oscillating amplitude of approximately $30 \mathrm{~nm}$ in Human Airway Smooth Muscle cells. Figure 2d shows approximately the same deformation in chondrocytes sonicated at the same amplitude of $170 \mathrm{kPa}$. Comparing the deformation induced by an ultrasound applied at an intensity of $14 \mathrm{kPa}$, Figs. 2a-c, to the deformation induced by an ultrasound intensity amplitude of $170 \mathrm{kPa}$, Figs. 2d-f, confirms that increasing the pressure amplitude will increase the deformation. However, if the ultrasound is applied at the resonant frequency the deformation induced by a $14 \mathrm{kPa}$ pressure amplitude, Fig. 2b, is approximately the same as that induced by ultrasound applied at a frequency outside of the resonant bandwidth with an intensity of $170 \mathrm{kPa}$, Fig. $2 \mathrm{~d}$ and $\mathrm{f}$. The theoretical model supports the frequency hypothesis theory where
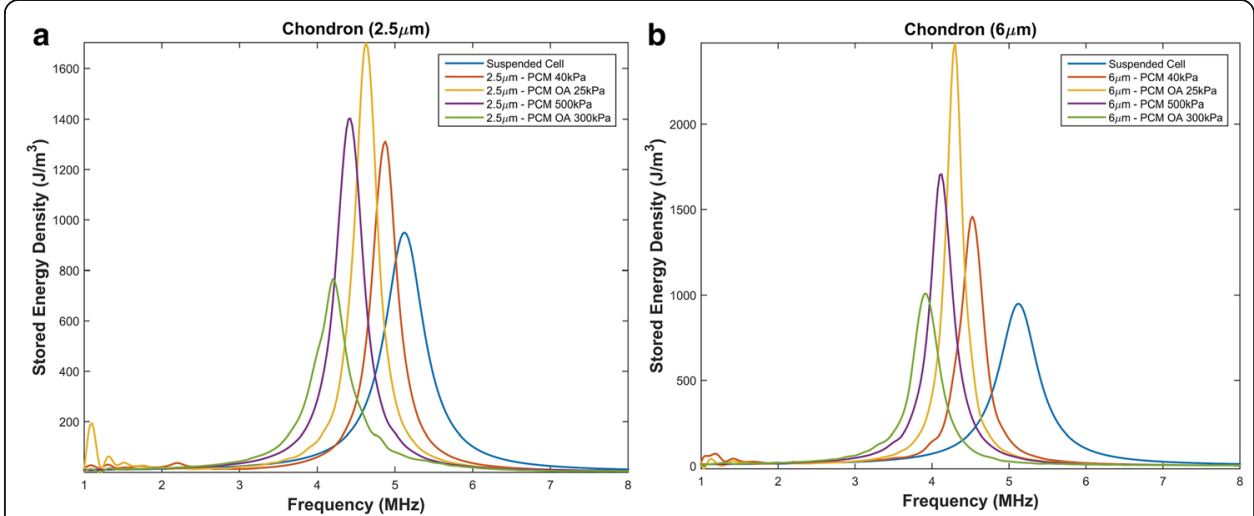

Fig. 4 Resonant frequency of chondrons with varying parameters. a PCM thickness of $2.5 \mu \mathrm{m}$ with a Young's modulus of $40 \mathrm{kPa}, 300 \mathrm{kPa}$ and osteoarthritic conditions. $\mathbf{b}$ PCM thickness of $6 \mu \mathrm{m}$ with a Young's modulus of $40 \mathrm{kPa}, 300 \mathrm{kPa}$ and osteoarthritic conditions 

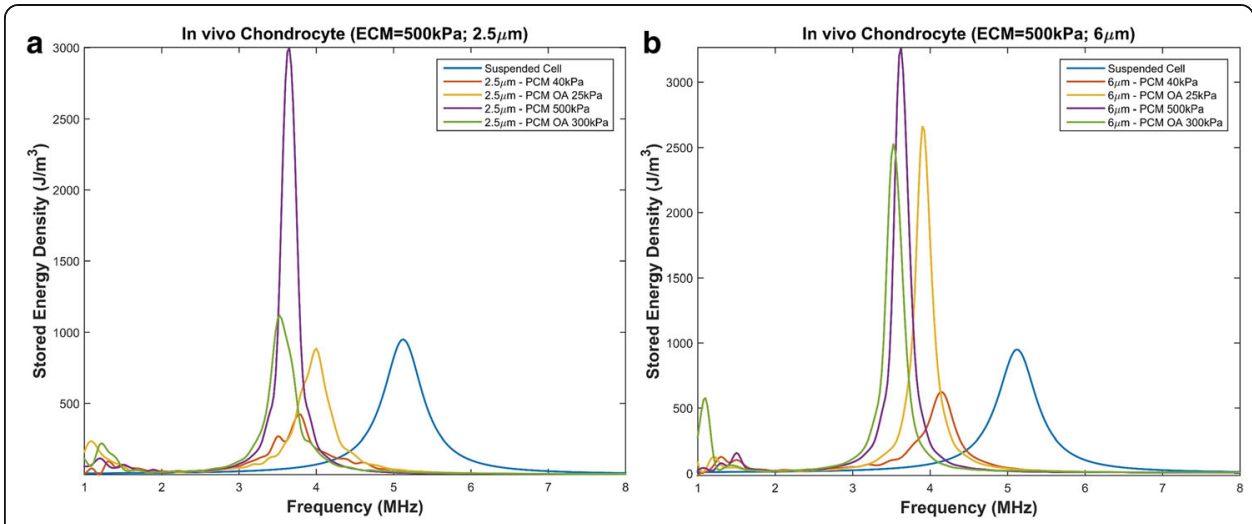

Fig. 5 Resonant frequency of chondrons embedded in an ECM with Young's modulus of $500 \mathrm{kPa}$ with PCM varying parameters. a PCM thickness of $2.5 \mu \mathrm{m}$ with a Young's modulus of $40 \mathrm{kPa}, 300 \mathrm{kPa}$ and osteoarthritic conditions. b PCM thickness of $6 \mu \mathrm{m}$ with a Young's modulus of $40 \mathrm{kPa}, 300 \mathrm{kPa}$ and osteoarthritic conditions

ultrasound application at the resonant frequency, even at low-intensities, will cause an even higher deformation than that induced by an ultrasound frequency outside of the resonant bandwidth. This deformation induced by the ultrasound results in the transmission of elastic energy (stored mechanical energy) into the cell. The reader is referred to [56] for additional details on the deformation magnitude of both the nucleus and cytoplasm using a nonlinear model.

\section{In vivo resonant frequency}

\section{Blood clot}

Microfracture techniques involve perforating the subchondral plate to promote blood flow in order to recruit MSCs from the bone marrow [1,2]. Differentiation of MSCs to chondrocytes follow, thus chondrocytes would be embedded in a blood clot following a microfracture procedure. The presence of a blood clot results in a slight shift to the left of the resonant frequency from $5.2 \mathrm{MHz}$ to approximately $4.8 \mathrm{MHz}$, as shown in Fig. 3a. A sequential step would involve the formation of the PCM. The presence of the
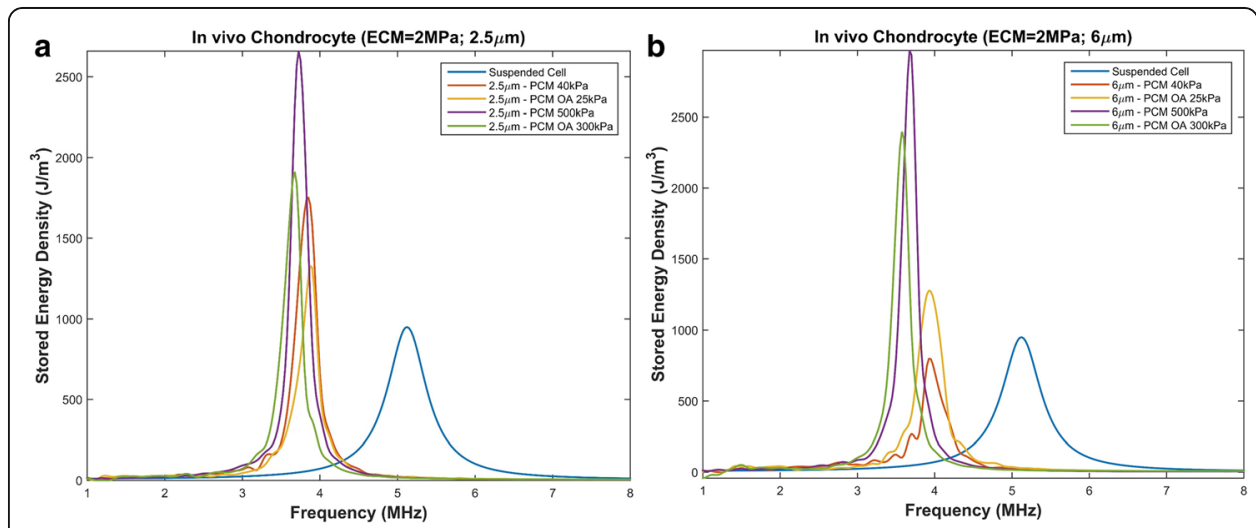

Fig. 6 Resonant frequency of chondrons embedded in an ECM with Young's modulus of 2 MPa with PCM varying parameters. a PCM thickness of $2.5 \mu \mathrm{m}$ with a Young's modulus of $40 \mathrm{kPa}, 300 \mathrm{kPa}$ and osteoarthritic conditions. b PCM thickness of $6 \mu \mathrm{m}$ with a Young's modulus of $40 \mathrm{kPa}, 300 \mathrm{kPa}$ and osteoarthritic conditions 
PCM with properties closer to the cell causes a greater shift, however a PCM with properties closer to native cartilage results in a $1 \mathrm{MHz}$ shift to the left, with a resonant frequency of 4.2 MHz. Ultrasound applied in the range of 4.2-4.8 MHz would be the optimal frequency for ultrasound enhanced cartilage restoration when applied following a microfracture procedure.

\section{Fibrin hydrogel}

ACI and newer cell-based techniques may involve cells suspended in hydrogels. Therefore, the hydrogel serves as the chondrocyte's initial mechanical environment. The use of fibrin gels have been shown to serve as a long-term stable hydrogel for cartilage restoration $[54,55]$, thus we modeled a suspended chondrocyte in a fibrin hydrogel. The presence of a hydrogel shifted the resonant frequency to approximately $3.7 \mathrm{MHz}$, shown in Fig. 3b. Modeling the cell surrounded by a PCM with a Young's modulus similar to native cartilage and embedded in the fibrin hydrogel resulted in the same resonant frequency, however, properties closer to the cell resulted in a higher resonant frequency of 4.1 MHz. Therefore, the optimal ultrasound frequency range for ultrasound induced cartilage restoration in conjunction with strategies involving fibrin hydrogels would be 3.7-4.1 MHz.

\section{Chondron}

A suspended chondron, which includes the chondrocyte and the surrounding PCM, was first modeled separately to see how the presence of the PCM effects the resonant frequency. As shown in Fig. 4 the presence of the healthy PCM causes the chondrocyte's resonant frequency to shift to the left (a decrease in the resonant frequency). Lower frequencies are beneficial in the application of ultrasound for cartilage restoration as higher frequencies attenuate faster leading to lower intensities at the defect site.

Alexopoulos [51] showed that the Young's modulus of non-osteoarthritic PCM is approximately $40 \mathrm{kPa}$. With this modulus, the resonant frequency of a healthy chondron with a thickness of $2.5 \mu \mathrm{m}$ is approximately $4.9 \pm .1 \mathrm{MHz}$ and $4.5 \pm .1 \mathrm{MHz}$ for a chondron with a thickness of $6 \mu \mathrm{m}$. The larger the PCM thickness the greater the shift in the resonant frequency. Since the thickness of the chondron is not uniform throughout the cartilage structure or in vivo experiments, sonicating suspended chondrons at a frequency within the range of $4.5-4.9 \mathrm{MHz}$ should maximize the beneficial bioeffects when treating chondrocytes embedded in healthy matrices. However, osteoarthritic chondrons have a greater impact on the resonant frequency with a larger decrease in the resonant frequency. Thus knowledge of the patient's specific properties or condition is important in designing a specific patient ultrasound regime.

Middle zone ECM (Young's modulus = $500 \mathrm{kPa}$ )

The frequency versus stored energy density of a chondron embedded in the extracellular matrix with a stiffness of $500 \mathrm{kPa}$ is shown in Fig. 5. The presence of the ECM causes an even greater shift towards lower frequencies when compared to a suspended chondron (Fig. 4) and a suspended chondrocyte. The thickness of the PCM has minimal effect on the resonant frequency. It is important to note that linear models, which is used in this study, results in an infinite peak at the resonant frequency. Although 
there does appear to be an increase in the amount of energy coupled to the cell versus that of a suspended chondrocyte in Figs. 4, 5 and 6 a nonlinear analysis must be conducted to determine the true limits of the resonant bandwidth and peak. Therefore, the peak magnitudes will not be discussed further.

\section{Deep zone ECM (Young's modulus = $2 \mathrm{MPa}$ )}

The frequency versus stored energy density of a chondron embedded in an ECM with a stiffness of $2 \mathrm{MPa}$ is shown in Fig. 6. The thickness of the PCM has a greater effect on normal healthy cartilage at lower Young's modulus. A PCM thickness of $2.5 \mu \mathrm{m}$ leads to a larger shift to the left than that with a thickness of $6 \mu \mathrm{m}$. The thickness does not impact the resonant frequency in the osteoarthritic conditions. From Figs. 5 and 6, one concludes that the stiffness of the ECM has minimal effect on the resonant frequency (comparing mechanical environments of $500 \mathrm{kPa}$ to $2 \mathrm{MPa}$ ).

As observed in Figs. 4 and 5 there are peaks in the stored mechanical energy in the range of $1-1.5 \mathrm{MHz}$ that appear to be dampened in stiffer matrices as seen in Fig. 6 . The stiffness of the ECM increases with depth of articular cartilage and the modulus of the deep zone is approximately $2 \mathrm{MPa}[48,51]$. Thus lower frequencies applied under the typical ultrasound regime for cartilage restoration would affect the middle zone of cartilage and have minimal impact on chondrocytes embedded in the deep zone. This could explain the variable results observed in vivo.

An optimal patient ultrasound regime should be based on the patient specific cartilage mechanical properties which is dependent on the surgical techniques involved. However, the properties are not always available and to physically determine them would be time consuming. Without the knowledge of the patient specific properties, applying ultrasound within the range $3.5-4.1 \mathrm{MHz}$ for native cartilage should maximize the ultrasound induced bioeffects throughout the entire depth of the cartilage. If a microfracture procedure was conducted than the optimal range would be $4.2-$ 4.8 MHz, however, if a surgical technique involving fibrin hydrogel was used then the optimal range is $3.7-4.1 \mathrm{MHz}$.

The Biot theory involves mechanical properties that are generally not found in literature such as the drained Young's modulus, thus the solid phase properties were used when not available. As a result a parameter analysis was conducted to understand the sensitivity of the resonant frequency to parameter values. The porosity and radius had the greatest impact on the resonant frequency. The lower the porosity the greater the shift to the left of the resonant frequency and the larger peaks in the lower frequencies. The larger the radius the greater the shift to the left of the resonant frequency. However, the smaller the radius, the greater the peaks are at the lower frequencies as shown in Fig. 7.

\section{Conclusions}

We have theoretically proved the resonant frequency hypothesis for cellular deformation. LIUS applied at the resonant frequency of the cell will induce deformation magnitudes on the order of those induced by high intensity ultrasound applied outside the resonant bandwidth. Additionally, we theoretically determined for the first time the resonant frequency of an in vivo chondrocyte embedded in its mechanical environment. Throughout literature there is a range of properties for the PCM and ECM reported, thus the resonant frequency was identified for a 

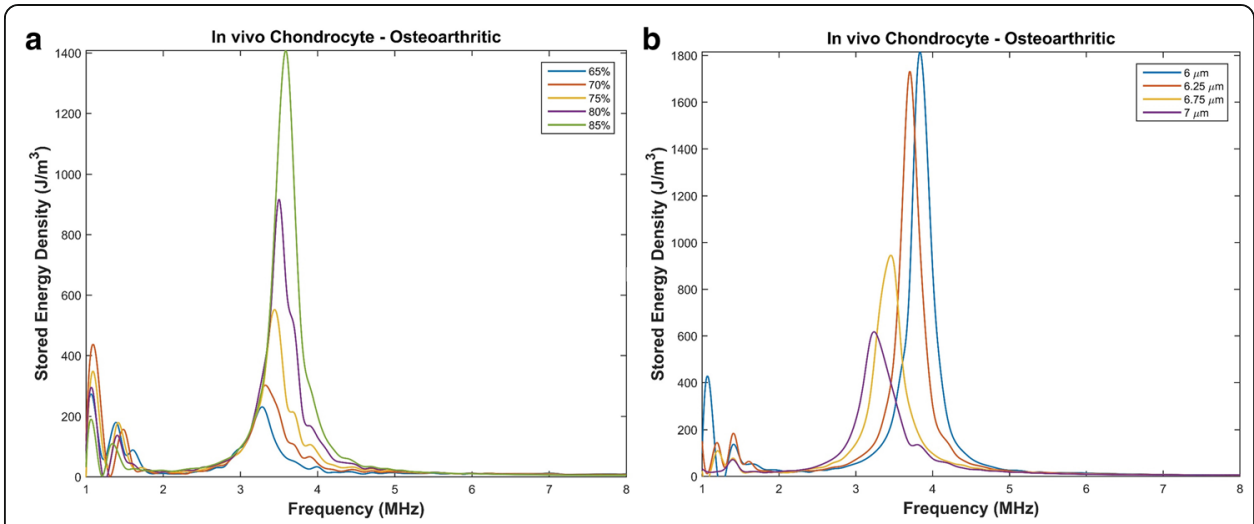

Fig. 7 Parameter Analysis. a Varying the porosity in an osteoarthritic environment with a PCM thickness of $3.75 \mathrm{~mm}$ and a PCM Young's modulus of $25 \mathrm{kPa}$ and ECM Young's modulus of $300 \mathrm{kPa}$. $\mathbf{b}$ Varying the radius in an osteoarthritic environment with a PCM thickness of $2.5 \mu \mathrm{m}$ and a PCM Young's modulus of $40 \mathrm{kPa}$ and ECM Young's modulus of $500 \mathrm{kPa}$

range of parameters and osteoarthritic conditions. Without the knowledge of patient specific mechanical properties an ideal frequency range for ultrasound application to induce maximum bioeffects would be $3.5-4.1 \mathrm{MHz}$ in native cartilage, 4.2-4.8 MHz when used in conjunction with microfracture techniques or 3.74.1 $\mathrm{MHz}$ if a fibrin hydrogel is used.

\section{Acknowledgements}

Not applicable.

Funding

Not applicable

\section{Availability of data and materials}

The datasets generated during the current study are available from the corresponding author on reasonable request.

\section{Authors' contributions}

ADM made substantial contributions to conception and design, analysis and interpretation of data. HJV and AS were involved in drafting the manuscript and agreed to be accountable for all aspects of the work. All authors read and approved the final manuscript.

\section{Ethics approval and consent to participate}

Not applicable.

\section{Consent for publication}

Not applicable.

\section{Competing interests}

The authors declare that they have no competing interests.

\section{Publisher's Note}

Springer Nature remains neutral with regard to jurisdictional claims in published maps and institutional affiliations.

Received: 4 July 2017 Accepted: 28 September 2017

Published online: 14 November 2017

\section{References}

1. Wang Q, Li Z, Fu Y, Wang Z, Wei M, Zhao B, et al. Effect of low-energy shock waves in microfracture holes in the repair of articular cartilage defects in a rabbit model. Chinese Medical Journal-Beijing. 2011;124(9):1386.

2. Knutsen G, Drogset JO, Engebretsen L, Grontvedt T, Ludvigsen TC, Loken S, et al. A Randomized Multicenter Trial Comparing Autologous Chondrocyte Implantation with Microfracture: Long-Term Follow-up at 14 to 15 Years. J Bone Joint Surg Am. 2016;98(16):1332-9.

3. Harris JD, Siston RA, Pan X, Flanigan DC. Autologous chondrocyte implantation: a systematic review. J Bone Joint Surg Am. 2010;92(12):2220-33.

4. Cole BJ, D'Amato M. Autologous chondrocyte implantation. Oper Tech Orthop. 2001;11(2):115-31. 
5. Ingber DE. Cellular mechanotransduction: putting all the pieces together again. FASEB J. 2006;20(7):811-27.

6. Eckstein F, Tieschky M, Faber S, Englmeier K, Reiser M. Functional analysis of articular cartilage deformation, recovery, and fluid flow following dynamic exercise in vivo. Anat Embryol. 1999;200(4):419-24.

7. Grodzinsky AJ, Levenston ME, Jin M, Frank EH. Cartilage tissue remodeling in response to mechanical forces. Annu Rev Biomed Eng. 2000;2(1):691-713.

8. Guilak F. Compression-induced changes in the shape and volume of the chondrocyte nucleus. J Biomech. 1995; 28(12):1529-41.

9. Buschmann MD, Gluzband YA, Grodzinsky AJ, Hunziker EB. Mechanical compression modulates matrix biosynthesis in chondrocyte/agarose culture. J Cell Sci. 1995;108:1497-508.

10. Iwashina T, Mochida J, Miyazaki T, Watanabe T, Iwabuchi S, Ando K, et al. Low-intensity pulsed ultrasound stimulates cell proliferation and proteoglycan production in rabbit intervertebral disc cells cultured in alginate. Biomaterials. 2006;27(3):354-61.

11. Zhang Z, Huckle J, Francomano CA, Spencer RG. The influence of pulsed low-intensity ultrasound on matrix production of chondrocytes at different stages of differentiation: an explant study. Ultrasound Med Biol. 2002;28(11):1547-53.

12. Kim Y, Bonassar LJ, Grodzinsky AJ. The role of cartilage streaming potential, fluid flow and pressure in the stimulation of chondrocyte biosynthesis during dynamic compression. J Biomech. 1995;28(9):1055-66.

13. Lee DA, Knight MM, Bolton JF, Idowu BD, Kayser MV, Bader DL. Chondrocyte deformation within compressed agarose constructs at the cellular and sub-cellular levels. J Biomech. 2000;33(1):81-95.

14. Mizrahi N, Zhou EH, Lenormand G, Krishnan R, Weihs D, Butler JP, et al. Low intensity ultrasound perturbs cytoskeleton dynamics. Soft Matter. 2012;8(8):2438-43.

15. Humphrey VF. Ultrasound and matter-Physical interactions. Prog Biophys Mol Biol. 2007:93(1):195-211.

16. Mishra P, Hill M, Glynne-Jones P. Deformation of red blood cells using acoustic radiation forces. Biomicrofluidics. 2014;8(3):034109.

17. Frazee S. Characterization and Implementation of Low Intensity Pulsed Ultrasound as a Tool to Apply Physical Load to Scaffolds and Bone Cells for Fracture Repair. Master's Theses. 2011;

18. Zhang S, Cheng J, Qin Y. Mechanobiological modulation of cytoskeleton and calcium influx in osteoblastic cells by short-term focused acoustic radiation force. PLoS One. 2012;7(6):e38343.

19. Hwang JY, Kim J, Park JM, Lee C, Jung H, Lee J, et al. Cell Deformation by Single-beam Acoustic Trapping: A Promising Tool for Measurements of Cell Mechanics. Sci Rep. 2016;6:27238.

20. Noriega S, Budhiraja G, Subramanian A. Remodeling of chromatin under low intensity diffuse ultrasound. Int J Biochem Cell Biol. 2012;44(8):1331-6.

21. Duda GN, Kliche A, Kleemann R, Hoffmann JE, Sittinger M, Haisch A. Does low-intensity pulsed ultrasound stimulate maturation of tissue-engineered cartilage? J Biomed Mater Res B Appl Biomater. 2004;68(1):21-8.

22. Cook SD, Salkeld SL, Popich-Patron LS, Rayaby JP, Jones DG, Barrack RL. Improved cartilage repair after treatment with low-intensity pulsed ultrasound. Clin Orthop Relat Res. 2001;3915:5231-43.

23. Takeuchi R, Ryo A, Komitsu N, Mikuni-Takagaki Y, Fukui A, Takagi Y, et al. Low-intensity pulsed ultrasound activates the phosphatidylinositol 3 kinase/Akt pathway and stimulates the growth of chcondrocytes in thee-dimensional cultures: a basic science study. Arthritis Res Ther. 2008;10(4):R77.

24. Zhang ZJ, Huckle J, Francomano CA, Spencer RG. The influence of pulsed low-intensity ultrasound on matrix production of chondrocytes at different stages of differentiation: an explant study. Ultrasound Med Biol. 2002; 28(11-12):1547-53.

25. Loyola Sanchez A, Ramirez Wakamatzu MA, Vazquez Zamudio J, Casasola J, Hernandez Cuevas C, Ramirez Gonzalez A, Galicia Tapia J. Effect of low-intensity pulsed ultrasound on regeneration of joint carilage inpatients with second and third degree osteoarthritis of the knee. Reumatol Clin. 2009;5(4):163-7.

26. Louw TM, Budhiraja G, Viljoen HJ, Subramanian A. Mechanotransduction of ultrasound is frequency dependent below the cavitation threshold. Ultrasound in Med. \& Biol. 2013;39(7):1303-19.

27. Cudahy E, Ellison WTA. review of the potential for in vivo tissue damage by exposure to underwater sound. Department of the Navy, Naval Submarine Medical Research. Laboratory. 2002;

28. Guha Thakurta S, Kraft M, Viljoen HJ, Subramanian A. Enhanced depth-independent chondrocyte proliferation and phenotype maintenance in an ultrasound bioreactor and an assessment of ultrasound dampening in the scaffold. Acta Biomater. 2014;10(11):4798-810.

29. Subramanian A, Turner JA, Budhiraja G, Guha Thakurta S, Whitney NP, Nudurupati SS. Ultrasonic bioreactor as a platform for studying cellular response. Tissue Eng Part C Methods. 2013;19(3):244-55.

30. Selmi TA, Verdonk P, Chambat P, Dubrana F, Potel JF, Barnouin L, et al. Autologous chondrocyte implantation in a novel alginate-agarose hydrogel: outcome at two years. J Bone Joint Surg Br. 2008;90(5):597-604.

31. Kim E, Guilak F, Haider MA. An axisymmetric boundary element model for determination of articular cartilage pericellular matrix properties in situ via inverse analysis of chondron deformation. J Biomech Eng. 2010;132(3):031011.

32. Wilusz RE, Sanchez-Adams J, Guilak F. The structure and function of the pericellular matrix of articular cartilage. Matrix Biol. 2014;39:25-32.

33. Guilak F, Alexopoulos LG, Haider MA, Ting-Beall HP, Setton LA. Zonal uniformity in mechanical properties of the chondrocyte pericellular matrix: micropipette aspiration of canine chondrons isolated by cartilage homogenization. Ann Biomed Eng. 2005;33(10):1312-8.

34. Guilak F, Alexopoulos LG, Upton ML, Youn I, Choi JB, Cao L, et al. The pericellular matrix as a transducer of biomechanical and biochemical signals in articular cartilage. Ann N Y Acad Sci. 2006;1068(1):498-512

35. Alexopoulos $L G$, Setton LA, Guilak F. The biomechanical role of the chondrocyte pericellular matrix in articular cartilage. Acta Biomater. 2005;1 (3):317-25.

36. Robinson DL, Kersh ME, Walsh NC, Ackland DC, de Steiger RN, Pandy MG. Mechanical properties of normal and osteoarthritic human articular cartilage. J Mech Behav Biomed Mater. 2016;61:96-109.

37. Atalla N, Allard J. Propagation of Sound in Porous Media: Modelling Sound Absorbing Materials 2e: John Wiley \& Sons; 2009.

38. COMSOL COMSOL 5.0 Acoustics Module User's Guide. COMSOL; 2014;45. 
39. Guilak F, Tedrow JR, Burgkart R. Viscoelastic properties of the cell nucleus. Biochem Biophys Res Commun. 2000; 269:781-6.

40. Trickey WR, Lee GM, Guilak F. Viscoelastic properties of chondrocytes from normal and osteoarthritic human cartilage. J Orthop Res. 2000;18:891-8.

41. Vaziri A, Mofrad MR. Mechanics and deformation of the nucleus in micropipette aspiration experiment. J Biomech. 2007:40:2053-62.

42. Trickey WR, Baaijens FP, Laursen TA, Alexopoulos LG, Guilak F. Determination of the Poisson's ratio of the cell: reccovery properties of chondrocytes after release from complete micropipette aspiration. J Biomech. 2006;39(1):78-87.

43. Bidehendi AJ, Korhonen RKA. finite element study of micropipette aspiration of single cells: Effect of compressibility. Comput Math Methods Med. 2012:192618.

44. Haider MA, Guilak F. Application of a three-dimensional poroelastic BEM to modeling the biphasic mechanics of cellmatrix interactions in articular cartilage (REVISION). Comput Methods Appl Mech Eng. 2007;196(31-32):2999-3010.

45. Kim E, Guilak F, Haider MA. The dynamic mechanical environment of the chondrocyte: A biphasic finite element model of cell-matrix ineractions under cyclic compressive loading. J Biomech Eng. 2008;130:061009.

46. Leipzig ND, Athanasiou KA. Unconfined creep compression of chondrocytes. J Biomech. 2005;38:77-85.

47. Mourad PD, Kargl SG. Acoustic properties of fluid-saturated blood clots (No. APL-UW-TR-2003). In: Washington Univ Seattle Applied Physics Lab; 2000

48. Wang CC, Guo XE, Sun D, Mow VC, Ateshian GA, Hung CT. The functional environment of chondrocytes within cartilage subjected to compressive loading: a theoretical and experimental approach. Biorheology. 2002;39(1, 2):11-25.

49. Töyräs J, Lyyra-Laitinen T, Niinimäki M, Lindgren R, Nieminen M, Kiviranta I, et al. Estimation of the Young's modulus of articular cartilage using an arthroscopic indentation instrument and ultrasonic measurement of tissue thickness. J Biomech. 2001;34(2):251-6.

50. Allen DM, Mao JJ. Heterogeneous nanostructural and nanoelastic properties of pericellular and interterritorial matrices of chondrocytes by atomic force microscopy. J Struct Biol. 2004;145(3):196-204.

51. Alexopoulos LG, Williams GM, Upton ML, Setton LA, Guilak F. Osteoarthritic changes in the biphasic mechanical properties of the chondrocyte pericellular matrix in articular cartilage. J Biomech. 2005;38(3):509-17.

52. Alexopoulos LG, Haider MA, Vail TP, Guilak F. Alterations in the mechanical properties of the human chondrocyte pericellular matrix with osteoarthritis. J Biomech Eng. 2003;125(3):323-33.

53. Guilak F, Mow VC. The mechanical environment of the chondrocyte: a biphasic finite element model of cell-matrix interactions in articular cartilage. J Biomech. 2000;33(12):1663-73.

54. Eyrich D, Brandl F, Appel B, Wiese H, Maier G, Wenzel M, et al. Long-term stable fibrin gels for cartilage engineering. Biomaterials. 2007;28(1):55-65.

55. Peretti GM, Xu J, Bonassar LJ, Kirchhoff $\mathrm{CH}$, Yaremchuk MJ, Randolph MA. Review of injectable cartilage engineering using fibrin gel in mice and swine models. Tissue Eng. 2006;12(5):1151-68.

56. Miller AD, Subramanian A, Viljoen HJA. nonlinear model of cell interaction with an acoustic field. J Biomech. 2017:56:83-8.

57. Minton AP. The influence of macromolecular crowding and macromolecular confinement on biochemical reactions in physiological media. J Biol Chem. 2001;276:10577-80.

58. Kuhn T, Ihalainen TO, Hyvaluoma J, Dross N, Willman SF, Langowski J, et al. Protein diffusion in mammalian cell cytoplasm. Plus One. 2011:e22962:6.

59. Lemmon EW, McLinden MO, Friend DG. Thermophysical properties of fluid systems. Linstrom PJ, Mallard WG, (eds). NIST Chemistry WebBook. NIST Standard Reference Database No. 69. Gaithersburg, MD; 2011

60. Kestin J, Sokolov M, Wakeham WA. Viscosity of liquid water in range 8-Degrees-C to 150-Degrees-C. J Phys Chem Ref Data. 1978;7:941-8

61. Rowat AC, Lammerding J, Herrmann H, Aebi U. Towards an integrated understanding of the structure and mechanics of the cell nucleus. BioEssays. 2008;30:226-36.

\section{Submit your next manuscript to BioMed Central and we will help you at every step:}

- We accept pre-submission inquiries

- Our selector tool helps you to find the most relevant journal

- We provide round the clock customer support

- Convenient online submission

- Thorough peer review

- Inclusion in PubMed and all major indexing services

- Maximum visibility for your research

Submit your manuscript at www biomedcentral.com/submit

C Biomed Central 